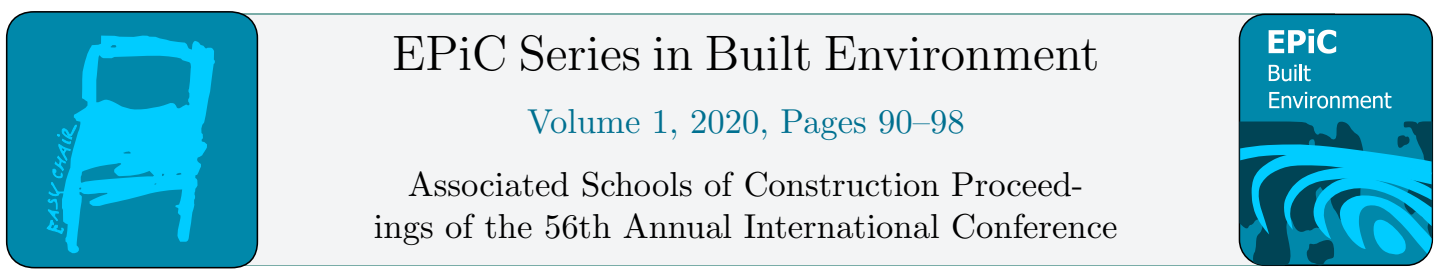

\title{
Development of a Required Service-Learning Course: Stakeholders' Perceptions and Lessons Learned
}

\author{
Lauren W. Redden and Robert A. Bugg \\ Auburn University \\ Auburn, Alabama
}

There is a growing movement for universities to include high-impact educational practices. This study explores the implementation and efficacy of one such practice in a construction management undergraduate program. During a recent curriculum revision, faculty decided to include a required service-learning course in the curriculum to enhance both student learning and civic engagement. The course assimilates all components of the construction process. Key assessments of the course include: written proposal \& preconstruction presentation to the owner, project update reports, a mid-semester site inspection, and a final presentation accompanied by a written reflection. Students and owners voluntarily completed surveys at the end of the semester to determine the elements requiring improvement, elements that should remain unchanged, and the perceived knowledge gain through the experience. The results indicate the project owners were satisfied and the students acknowledged learning benefits. Owners, students and faculty all noted major challenges/frustrations with the course and the need for improvement. The paper summarizes the data to evaluate the efficacy of the required course and highlights lessons learned to improve the course. Dissemination of the results may be useful in starting or improving service-learning courses at other institutions.

Key Words: service-learning, construction education, curriculum, student learning, community engagement, high-impact educational practices

\section{Introduction and Review of Literature}

Many in higher education recognize that gaining real-world experience as undergraduate students decreases their learning curve upon entering the industry, making them more resourceful and effective industry professionals (Brncich, A., Shane, J., Strong, K., \& Passe, U., 2011; Cline and Kroth, 2008). As each student matriculates through the construction management curriculum, the coursework should develop each student's capabilities by providing opportunities to apply the course content in the framework of experiential learning activities. Farrow and Burt (2018) found students that participated in small scale service-learning projects, international study, competition teams, and/or an industry internships connected those experiences to a more profound level of learning. 
High-impact educational practices share several traits, according to Kuh (2008): "they demand considerable time and effort, facilitate learning outside of the classroom, require meaningful interactions with faculty and students, encourage collaboration with diverse others, and provide frequent and substantive feedback." Like other land grant institutions, Auburn University has "impactful service" as one of its strategic goals. This includes innovation and community engagement to enhance the quality of life in Alabama and beyond. (Auburn University, 2019). Prior to the addition of community engagement to the university's strategic goals, the McWhorter School of Building Science has long been active in offering opportunities for community engagement to the students in the program. For over 25 years, several faculty members spearheaded the incorporation of service projects as a component in various courses in the curriculum.

As part of a recent curriculum review, the faculty made the decision to increase the McWhorter School of Building Science's commitment to community engagement and high-impact educational practices by adding a required standalone service-learning (SL) course as part of the new curriculum. The 'new' SL course is offered in the penultimate semester prior to graduation and is designed to integrate all components of the construction process including planning, engagement and collaboration with stakeholders, management, safety, quality, and execution while at the same time enhancing community engagement.

Service-learning is a widely-used, well-researched, and respected high-impact educational practice of the pedagogies related to civic engagement (Finley, 2011; Gelmon, S.B., Holland, B.A. \& Spring, A., 2018). Service-learning is defined as "a form of experiential education in which students engage in activities that address human and community needs together with structured opportunities intentionally designed to promote student learning and development" (Jacoby, 1996). Multiple studies into the integration of SL into construction education have shown the value of this pedagogical practice, as opposed to solely delivering course content in the "traditional" way of lecturing. The results of integrating a weekend SL project for students in a project management course at the University of Washington indicated hands-on projects that tie to the concurrent classroom instruction can provide a powerful learning vehicle and is well suited to bring real-world industry application into the course (Brown, 2000).

One primary gap in previous research is the development and implementation of a required course in the construction management curriculum that features large-scale SL construction projects as the primary requirement for successful completion of the course. Several enriching SL elective courses have been highlighted in recent years. In 2010, Auburn University (Farrow, C.B., Kramer, S.W., \& Meek, D., 2011) initiated a short-term study abroad elective course with a humanitarian aspect incorporated for the students enrolled to assist in the construction of an after school care center in Quito, Ecuador, for underprivileged children in partnership with the non-profit organization Servants in Faith and Appropriate Technology (SIFAT). Colorado State University recently published on the development and success of a service-learning elective course (CON 464 Construction Leadership) which began in 2011, occurs each spring semester, and is centered on one larger-scale servicelearning project (SLP) for the total class to work on throughout the semester. The elective course has "an established structured selection of students that wish to enroll in the course and participate in a SLP.” (Olbina, S., Mehany, M. \& Jesse, K., 2018). While SL elective courses are well-documented as valuable and enriching to those students that participate, students who are unable to participate because they were not selected or could not afford additional fees are not able to benefit from the learning experiences afforded by SL elective courses. 
At the core of SL curricula is reflection (Ash \& Clayton, 2009). "As a form of experiential education, $\mathrm{SL}$ is based on the pedagogical principle that learning and development do not necessarily occur as a result of the experience itself. Rather, they occur as a result of reflection intentionally designed to promote learning and development" (CAS, 2012). Reflection can take many forms for both students and community partners. The research to date notes reflection by the students as a significant component in service-learning. However, a critical gap in existing construction education literature is only reporting on the student reflection of the service-learning activity or project. It is the researcher's belief that receiving all stakeholders' feedback and incorporating it will improve the learning experience for all involved in the projects (Ferrari and Worrall, 2000; Honnet and Poulen, 1989). The feedback and reflection from the non-profit clients (owners) and the instructor of the course are equally as critical to consider the reflection a well-rounded evaluation of the course and the success/failure of the learning.

For each of the first two semesters the new required SL course was offered at McWhorter School of Building Science, there were two cohorts of 30 students each. Each cohort was divided into three, 10student construction teams. In order to select suitable projects, shortlisted non-profit organizations (owners) participated in a request for proposal (RFP) process. Owners submitted a written response summarizing the scope of their proposed projects(s). After the RFP responses were vetted by the Service-Learning Coordinator and course instructor, owners were invited to present their projects to the student construction teams in the semester prior to the semester when work would commence. Each student team selected the project they would work on for the upcoming semester. When the next semester began, the student teams were required to prepare and submit a Site Specific Accident Prevention Plan, a cost estimate, and construction schedule for their selected project. Each student team made an oral presentation ('pitch') to the owner and course instructor summarizing these documents prior to the start of work. Each team received notice to proceed for the project after receiving the owner's written approval of budgets and schedules. The student teams spent the balance of the semester executing the construction of the projects. In developing the course content, the following American Council for Construction (ACCE) Student Learning Outcomes (SLOs) were determined to be aligned with the course objectives:

- ACCE SLO 1 - Create written communications appropriate to the construction discipline

- ACCE SLO 2 - Create oral presentations appropriate to the construction discipline

- ACCE SLO 3 - Create a construction safety plan

- ACCE SLO 4 - Create construction project cost estimates

- ACCE SLO 5 - Create construction project schedules

- ACCE SLO 8 - Analyze methods, materials, and equipment used to construct projects

- ACCE SLO 10 - Apply electronic-based technology to manage the construction process

- ACCE SLO 12 - Understand different methods of project delivery and the roles and responsibilities of all constituencies involved in the design and construction process

- ACCE SLO 15 - Understand construction quality assurance and control

- ACCE SLO 18 - Analyze methods, materials, and equipment used to construct projects

The students receive two (2) credit hours for completing the course. The following is student assessment and evaluation information from the course syllabus:

- Written Proposal, Estimate, Schedule, Safety Plan \&Quality Control Plan (ACCE SLOs 1,3-5,10,12,15,18)

- Oral Presentation of the Proposal to the Client (ACCE SLOs 2-5,10,12,15,18) $10 \%$

- Communication Reports (ACCE SLOs 3,8,15,18) 
- Mid-Project Inspection (safety procedures, quality, interaction with owner, $20 \%$ and involvement of team members) (ACCE SLOs 3,8,15,18)

- Completion of Service-Learning Construction (ACCE SLO 8)

- Final Presentation (written and visual documentation, reflection of process) (ACCE SLOs 2,8)

The balance of this paper describes and analyzes the perceptions of students, instructor and owners concerning the efficacy of the current SL course in the McWhorter School of Building Science undergraduate curriculum at Auburn University.

\section{Research Methodology}

In order to evaluate the efficacy of the course, the researchers surveyed participating students and the owners of the projects at the conclusion of the course for the 2018 Fall semester and the 2019 Spring semester, which were the first two semesters the course was offered.

The surveys were developed based on a literature review and multiple brainstorming sessions that included faculty and staff involved in other SL activities in the construction management curriculum. All the surveys were administered on paper, and they were distributed by the principle investigators to all students and owners at the end of the semester final presentation day. It is important to note the principal investigators of this study were not the instructor of record for the course in the first two semesters when data was collected. A qualitative approach with thematic coding of all open-ended questions was used to determine common themes from the three stakeholder groups (students, owners and instructor). This allowed the principal investigator to gain perspective from all three different stakeholders, thus getting well-rounded information leading to a more accurate study.

The student survey was structured to elicit responses regarding the students' perception of their preparedness in the areas of cost estimating, construction scheduling, and safety planning. Answers to each question were provided with a range of five answers (tied to a Likert Scale). In addition, the students were asked a series of open-ended questions concerning the three best things of the course from a learning perspective, the three aspects of the course needing improvement, how much time they spent planning and constructing their project, and whether or not the project was completed.

The owner survey was structured to gain the owners perspective of the preparedness of the students in the areas of cost estimating, safe execution of the work, execution of the work to produce a quality product, and timely performance. Owners were also asked to rate their satisfaction for their project in the areas of quality, amount of work completed, professionalism of students, and project cost.

Answers to each question were provided with a range of five answers (tied to a Likert Scale). In addition, the owners were asked a series of open-ended questions concerning the biggest challenge they faced on the project, the biggest challenge the students faced on the project, and whether or not they would participate with a service-learning course in the future. They were also asked to provide specific ways the student teams could improve their performance.

In addition, the instructor for the course was interviewed to solicit their perspectives concerning the strengths, weaknesses, and overall effectiveness of the course. The semi-structured interview did not produce any significant findings noteworthy to included herein. Due to the length limitations of this paper, the researchers incorporated minimal instructor data herein. The researchers will continue collect data as the course continues to be offered and will be included in future research work. 


\section{Results and Discussion}

Each semester, a total of six (6) projects were executed (12 projects total in both semesters); and for each project, a student team of ten (10) was involved in the execution (total of 120 students in both semesters).There were 53 respondents of 60 students (88.3\% response rate) in the Fall 2018 cohort and 33 respondents out of 60 students (55\% response rate) in the Spring 2019 cohort. It should be noted that the completion of the surveys for this study were voluntary and not required to be completed as a part of each student's assessment in the course.

The student survey began with collecting central facts on each project. Table 1 below summarizes the disparity in travel distance and student workload depending on the team's project.

Table 1. Travel distance and physical time executing the service-learning projects.

\begin{tabular}{lcccccc}
\hline & \multicolumn{3}{c}{ Distance from campus (miles) } & \multicolumn{3}{c}{ Student } \\
& Avg. & High & Low & Avg. & High & Low \\
\hline F 2018 & 32.0 & 74.6 & 10.6 & 77.7 & 115.7 & 44.3 \\
S 2019 & 5.7 & 10.8 & 1.0 & 60.5 & 86.7 & 46.8 \\
\hline
\end{tabular}

The student work hours (Table 1) data is the summary of each student's response to the question "Approximately how many total hours did you personally spend working on executing the assigned service project?"

In the Fall 2018 semester, only one team out of six completed the original scope of their project. In the Spring 2019 semester, this increased to five teams out of six completing the original scope of their projects. For Fall 2018, taking the average number of hours worked each team generally expended an average of 777 man-hours per construction project (10 team members $x 77.7 \mathrm{hrs}=777$ man-hours). For the Spring 2019 cohort, each team expended an average of 605 man-hours hours per project (10 team members x 60.5 hours $=605$ man-hours). Both of these figures far exceed the original intent for the teams to expend approximately 400 man-hours constructing each project.

The reduction in travel distance and the reduction in disparity of average hours worked between the Fall 2018 semester and the Spring 2019 semester is the result of a review by the instructor and the SL Coordinator to select projects closer to campus with a reduced scope. The faculty also followed a more systematic approach to vetting owners in order to insure each project scope was well defined and a more comprehensive preconstruction effort was completed prior to the start of the Spring 2019 semester. The improved selection of projects also resulted in a higher completion rate. However, as can be seen on the data below, issues remained to exist in several key areas that must be resolved.

Table 2 below summarizes the students' perspective concerning their preparedness to execute the course deliverables and their preparedness to apply their prior learning to their SL project.

Table 2. Students' perception of their preparedness

\begin{tabular}{|c|c|c|c|c|c|c|}
\hline & $\begin{array}{c}\text { Completely } \\
\text { Prepared }\end{array}$ & $\begin{array}{c}\text { Somewhat } \\
\text { Prepared }\end{array}$ & Neutral & $\begin{array}{l}\text { Somewhat } \\
\text { Unprepared }\end{array}$ & $\begin{array}{l}\text { Completely } \\
\text { Unprepared }\end{array}$ & $\begin{array}{l}\text { Avg. } \\
\text { Score }\end{array}$ \\
\hline F 2018 & & & & & & \\
\hline Estimate & 9 & 22 & 7 & 2 & 13 & 3.23 \\
\hline Schedule & 12 & 17 & 6 & 7 & 11 & 3.23 \\
\hline
\end{tabular}




\begin{tabular}{lcccccc}
$\begin{array}{l}\text { Safety Plan } \\
\text { S 2019 }\end{array}$ & 12 & 20 & 8 & 7 & 6 & 3.47 \\
Estimate & 12 & 13 & 3 & 3 & 2 & 3.91 \\
Schedule & 9 & 13 & 6 & 2 & 2 & 3.67 \\
Safety Plan & 15 & 11 & 4 & 2 & 1 & 4.12 \\
\hline
\end{tabular}

As can be seen from the responses in Table 2, the majority of the students in both cohorts considered themselves either "Completely Prepared" or "Somewhat Prepared" to create a cost estimate, construction schedule, and site specific safety plan for their SL project. However, it is noted that the overall students' perception of their preparedness for the Spring 2019 cohort was considerably higher than that of the Fall 2018 cohort for all categories. The reason for this difference cannot be determined based on available data, and presents a potential area of future research.

Table 3 below summarizes the students' overall evaluation in relation to the best aspects of the course and those aspects of the course needing improvement.

Table 3. Student evaluations of the course.

\begin{tabular}{llclc}
\hline Cohort & \multicolumn{1}{c}{ 3 Best Aspects } & $\begin{array}{c}\text { \# of } \\
\text { Responses }\end{array}$ & $\begin{array}{c}\text { 3 Aspects Needing } \\
\text { Improvement }\end{array}$ & $\begin{array}{c}\text { \# of } \\
\text { Responses }\end{array}$ \\
\hline F 2018 & • Hands-on experience & 58 & • Instructor issues & 63 \\
& - Teamwork/collaboration & 25 & - Lack of "precon prep" & 48 \\
& - Relationship w/owner & 22 & - Travel time/distance & 12 \\
S 2019 & - Hands-on experience & 36 & - Lack of "precon prep" & 27 \\
& - Communication & 20 & - Instructor issues & 21 \\
& - Time Management & 6 & - Workhours/workload & 16 \\
& - Teamwork/collaboration & 6 & & \\
\hline
\end{tabular}

Both cohorts agreed that the best aspect of the course was the hands-on experience gained from planning and constructing their SL project. Both cohorts appreciated the value of taking what they had learned in the classroom and applying their knowledge to a real-world project. Other aspects of the course that the students liked were the teamwork skills they developed, developing their communication skills, the relationship they developed with the non-profit owners, and developing time management skills. Intuitively, these answers were not unexpected and confirm accepted theories concerning the value of service-learning courses.

As for aspects of the course that needed improvement, both cohorts noted the major lack of preconstruction preparation by the owners including permitting and scope definition. On several of the projects, the lack of proper scope definition led to major change orders that added significant work and prevented the projects from being completed. Delays in permitting compressed the construction timeline on several projects which also affected contract completion. Both cohorts also noted several issues with the instructor for the course. The majority of these complaints centered on difficulty in getting timely answers/decisions when construction issues arose. Many students criticized an overall lack of instructor availability and a lack of guidance throughout the semester. In addition to the student feedback collected, the non-profit owners provided responses on the course and their specific project.

A total of 18 owner representatives responded to the voluntary survey. Fall 2018 had nine (9) respondents and Spring 2019 had nine (9) respondents. The number of owner respondents is greater 
than the total number of projects (12), because some projects had more than one owner representative at the final presentations at the end of the semester. Table 4 below summarizes the owners' satisfaction with their project(s) at the end of the semester.

Table 4. Owners' satisfaction with project.

\begin{tabular}{lcccccc}
\hline & $\begin{array}{c}\text { Completely } \\
\text { Satisfied (5) }\end{array}$ & $(4)$ & $\begin{array}{c}\text { Satisfied } \\
(3)\end{array}$ & $(2)$ & $\begin{array}{c}\text { Very } \\
\text { Unsatisfied (1) }\end{array}$ & $\begin{array}{c}\text { Avg. } \\
\text { Score }\end{array}$ \\
\hline$\quad$ F 2018 & & 1 & 0 & 0 & & \\
Quality & 8 & 2 & 0 & 0 & 0 & 4.89 \\
$\begin{array}{l}\text { Completion } \\
\text { Professionalism }\end{array}$ & 7 & 3 & 0 & 0 & 0 & 4.78 \\
$\quad$ S 2019 & & 2 & 0 & 0 & 0 & 4.78 \\
Quality & 7 & 4 & 0 & 0 & 0 & 4.56 \\
Completion & 5 & 2 & 1 & 1 & 0 & 4.22 \\
Professionalism & 5 & & & & & \\
\hline
\end{tabular}

Generally, the data collected from the owners demonstrates satisfaction with the students' abilities and the teams' execution of the projects. There were two outliers in the owner evaluation of the Spring 2019 cohort. One owner rated professionalism as a " 3 " and another rated it as a " 2 ". It is evident that overall the owners were satisfied with the execution of their projects absent these outliers.

The owners were asked "What was the biggest challenge the students faced on this project in your opinion?" This question produced consistent thematic responses. The following list is a summary of the most frequently noted responses to this question:

- Design changes during construction

- Crew productivity and look-ahead scheduling

- Confidence in knowledge and decision making

- Cohesion and teamwork within their own team

- Communication means, methods and frequency with the owner

The owners were asked "What was the biggest challenge you faced on this project in your opinion?" This question produced a wide range of responses. The following list is a summary of the most common responses:

- Incomplete design at the start of the semester/changes in the original scope

- Lack of availability of the students consistently throughout the semester / student time management issues

- Weather and unforeseen conditions

- Communication means, methods and frequency with the students

When asked "Would you participate in this opportunity again in the future?," seventeen out of eighteen (17/18) owners stated they would participate in any future opportunities. One owner answered this question with a "maybe," and provided the reason "I do not have another project at this time." As challenging as the collaboration was for many owners, the majority of them recognized the immense benefit of the course and their involvement in each project. Owners included statements in the open-ended "additional remarks" portion of the survey such as:

- These students provided us with an outstanding finished product. We love being a part of this program and enjoy having the students leave their mark on the community with us. -Non-

\section{Profit Project Owner 11}


- The student team possessed skills that complements the other stakeholders in the project, and their help proved critical at key moments in the process. -Non-Profit Project Owner 9

\section{Conclusions, Limitations and Future Research}

Experiential learning, and service-learning in particular, is a critical high-impact educational practice for many colleges and universities today. This paper describes the creation of a new required servicelearning based course at Auburn University in the McWhorter School of Building Science, where the focus was to foster deeper awareness of metacognitive knowledge and enhance each student's opportunity to participate in civic engagement. Survey results from participating students and the owners of the projects at the conclusion of the course for the 2018 Fall semester and the 2019 Spring semester highlighted areas of improvement and sustainable educational benefits of the course.

Overall, the large majority of non-profit clients (owners) were satisfied with the end product they each received. However, owners did not find the collaboration easy or seamless, and their involvement in the course did create challenges for most owner entities. The crucial matters this study identifies as fundamental for owners to have the "best experience" are: (1) to have a fully designed, completely scoped project; (2) the project must have obtained all necessary permits for the construction prior to the start of the semester; and (3) a thorough communication plan for both the student teams and owner representatives would eliminate much of the communication issues. The faculty involved in the course also must play a major role in managing the owner expectations and insuring owner relations are strong throughout the entire semester, and not leave that solely to the students to manage themselves.

Two encouraging findings from the student responses include: (1) their advancements in field construction knowledge and appreciation for the skills tradesmen and women contribute to a project; and (2) their appreciation of the course being 'real-world' in the learning style (complex team dynamics and balancing multiple relationships simultaneously). In addition, students expressed in their reflections of the course sincere gratitude to have been provided the opportunity to engage and contribute to the needs in the surrounding communities while strengthening themselves as construction manager. The instructor workload for this course is significant due to the nature of the projects and the volume of projects each semester (6 projects each semester). The students repeatedly noted the instructor's availability to provide guidance when needed was an issue throughout both semesters. Also, constant scope changes from the owners delayed the work and reduced project team morale as the semester progressed. The last issue found in the student survey data is the need to evaluate the credit hours for the course to the amount of work expected to be accomplished by the student teams.

The researchers and faculty involved in teaching the 'new' SL course recognize there are great improvements and/or changes to make to the course structure in order for this to be sustainable for years to come. This study was limited to two semesters of data collection. Future research will include replicating this study during additional semesters of the course, as well as tracking any similar courses at peer institutions that may have been recently created and not documented in the literature.

\section{References}

Ash, S. L. and Clayton, P.H. (2009). Learning through critical reflection: A tutorial for servicelearning students. Raleigh, NC. 
Auburn University. (2019). 2019-2024 Auburn University Strategic Plan. Auburn, AL.

Brown, K.A. (2000). Developing Project Management Skills: A Service-Learning Approach. Project Management Journal, 31:4, 53-58.

Brncich, A., Shane, J., Strong, K., \& Passe, U. (2011). Using Integrated Student Teams to Advance Education in Sustainable Design and Construction. International Journal of Construction Education and Research, 7:1, 22-40.

Cline, R.C. and Kroth, M. (2008). The Challenges of Using Service Learning in Construction Management Curricula. International Journal for Service Learning in Engineering, 3:1, 1-8.

Council for the Advancement of Standards in Higher Education (CAS). (2012). CAS Professional Standards for Higher Education. ( $\left.8^{\text {th }} \mathrm{ed}\right)$. Washington, D.C.

Farrow, C.B. and Burt, R. (2018). High-Impact Educational Practices in Construction Education: An Evaluation of Student Involvement and Perceived Value. In: Gorse, C. and Neilson, C.J. (eds) Proceedings of the 34 th Annual ARCOM Conference, 3-5 September. Belfast, UK.

Farrow, C.B., Kramer, S.W., \& Meek, D. (2011). International Short-Term Service Learning Trip: Assessing Student Perceptions. In the Proceedings of the 47th ASC Annual International Conference. Omaha, NE, April 6-9.

Ferrari, J.R. and Worrall, L. (2000). Assessments by Community Agencies: How "the Other Side" Sees Service-Learning. Michigan Journal of Community Service-Learning, v7, 35-40.

Finley, A. (2011). Civic learning \& democratic engagements: A review of the literature on civic engagement in postsecondary education. Washington, DC. Assoc. of American Colleges \& Universities.

Gelmon, S.B., Holland, B.A. \& Spring, A. (eds). (2018). Assessing service-learning and civic engagement: Principles and techniques $\left(2^{\text {nd }}\right.$ ed.). Sterling, VA: Stylus Publishing, LLC

Honnet, E.P. and Poulen, S.J. (1989). A Wingspread special report. Racine, WI: The Johnson Foundation.

Jacoby, B. (ed.). (1996). Service-learning in higher education: Concepts and practices. San Francisco, CA: Jossey-Bass.

Kuh, G. D. (2008). High-Impact Educational Practices: What They Are, Who Has Access to Them and Why They Matter. Washington, DC: Association of American Colleges \& Universities.

Olbina, S., Mehany, M. \& Jesse, K. (2018). Service Learning Project (SLP) Implementation and Assessment in a Construction Management Program - A Case Study. Proceedings of the 54th ASC Annual International Conference, Minneapolis, MN, April 18-21 